\title{
Peak oxygen uptake and breathing pattern in COPD patients - a four-year longitudinal study
}

Bente Frisk ${ }^{1,2 *}$, Jon A. Hardie², Birgitte Espehaug ${ }^{1}$, Liv I. Strand ${ }^{3,4}$, Rolf Moe-Nilssen ${ }^{3}$, Tomas M. L. Eagann 2,5 , Per S. Bakke ${ }^{2}$ and Einar Thorsen ${ }^{2,6}$

\begin{abstract}
Background: Activities of daily living in patients with chronic obstructive pulmonary disease (COPD) are limited by exertional dyspnea and reduced exercise capacity. The aims of the study were to examine longitudinal changes in peak oxygen uptake $\left(\dot{V} \mathrm{O}_{\text {peak }}\right)$, peak minute ventilation $\left(\dot{V}_{\text {Epeak }}\right)$ and breathing pattern over four years in a group of COPD patients, and to examine potential explanatory variables of change.

Methods: This longitudinal study included 63 COPD patients, aged 44-75 years, with a mean forced expiratory volume in one second $\left(\mathrm{FEV}_{1}\right)$ at baseline of $51 \%$ of predicted $(\mathrm{SD}=14)$. The patients performed two cardiopulmonary exercise tests (CPETs) on treadmill 4.5 years apart. The relationship between changes in $\dot{V}_{2}{ }_{2 p e a k}$ and $\dot{V}_{\text {Epeak }}$ and possible explanatory variables, including dynamic lung volumes and inspiratory capacity (IC), were analysed by multivariate linear regression analysis. The breathing pattern in terms of the relationship between minute ventilation $\left(\dot{V}_{E}\right)$ and tidal volume $\left(V_{T}\right)$ was described by a quadratic equation, $V_{T}=a+b \cdot \dot{V}_{E}+c \cdot \dot{V}_{E}^{2}$, for each test. The $V_{T \max }$ was calculated from the individual quadratic relationships, and was the point where the first derivative of the quadratic equation was zero. The mean changes in the curve parameters (CPET2 minus CPET1) and $V_{\text {Tmax }}$ were analysed by bivariate and multivariate linear regression analyses with age, sex, height, changes in weight, lung function, IC and inspiratory reserve volume as possible explanatory variables.
\end{abstract}

Results: Significant reductions in $\dot{V}_{2 \text { peak }}(p<0.001)$ and $\dot{V}_{\text {Epeak }}(p<0.001)$ were related to a decrease in resting IC and in $\mathrm{FEV}_{1}$. Persistent smoking contributed to the reduction in $\dot{\mathrm{V}}_{2 \text { peak. }}$. The breathing pattern changed towards a lower $\mathrm{V}_{T}$ at a given $\dot{V}_{E}$ and was related to the reduction in $\mathrm{FEV}_{1}$.

Conclusion: Increasing static hyperinflation and increasing airway obstruction were related to a reduction in exercise capacity. The breathing pattern changed towards more shallow breathing, and was related to increasing airway obstruction.

\section{Background}

Activities of daily living in patients with chronic obstructive pulmonary disease (COPD) are limited by exertional dyspnea and reduced exercise capacity $[1,2]$. Exertional dyspnea appears to be related to the increased work of breathing associated with a restriction of tidal volume $\left(\mathrm{V}_{\mathrm{T}}\right)$ expansion [3]. A reduction in exercise capacity measured as peak oxygen uptake $\left(\dot{\mathrm{V}}_{2 \text { peak }}\right)$ has

\footnotetext{
* Correspondence: bente.frisk@hib.no

'Centre for Evidence-Based Practice, Bergen University College, Bergen, Norway

${ }^{2}$ Department of Clinical Science, University of Bergen, Bergen, Norway Full list of author information is available at the end of the article
}

been found to be related to ventilatory limitations $[4,5]$, pulmonary gas exchange abnormalities [6], peripheral muscle dysfunction $[7,8]$ or any combination of these factors. COPD is a progressive disease with an increased rate of decline in forced expiratory volume in one second $\left(\mathrm{FEV}_{1}\right)[9,10]$. However, the relationship between $\mathrm{FEV}_{1}$ and $\mathrm{V}_{2} \mathrm{O}_{2 \text { peak }}$ is considered weak, and lung function by itself is a poor predictor of exercise capacity [11].

Studies of longitudinal changes in $\dot{\mathrm{V}} \mathrm{O}_{2 \text { peak, }}$ peak minute ventilation $\left(\dot{\mathrm{V}}_{\text {Epeak }}\right)$ and breathing pattern in COPD are scarce. As far as we know, the longitudinal change in $\dot{\mathrm{V}} \mathrm{O}_{2 \text { peak }}$ has only been examined in one previous study [12]. A reduction in $\dot{\mathrm{V}}_{2 \text { peak }}$ over five years

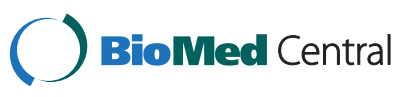


was found to be related to a reduction in maximal tidal volume $\left(\mathrm{V}_{\text {Tmax }}\right)$ and $\dot{\mathrm{V}}_{\text {Epeak }}$, and the decrease in $\dot{\mathrm{V}} \mathrm{O}_{\text {2peak }}$ was associated with the decrease in $\mathrm{FEV}_{1}$. However, only male Japanese patients were included in that study and the breathing pattern was not examined. We are not aware of any studies that have examined the longitudinal changes in $\dot{\mathrm{V}}_{2 \text { peak }}$ and breathing pattern in COPD patients of Caucasian origin including both genders.

The breathing pattern in terms of the relationship between minute ventilation $\left(\dot{V}_{E}\right)$ and $V_{T}$ during incremental exercise has been described by Gallagher [13]. In the first phase, there is an almost linear relationship between $\dot{V}_{\mathrm{E}}$ and $\mathrm{V}_{\mathrm{T}}$. In the second phase, the increase in $\dot{\mathrm{V}}_{\mathrm{E}}$ is mainly caused by an increase in breathing frequency $\left(\mathrm{B}_{\mathrm{f}}\right)$, and a smaller increase in $\mathrm{V}_{\mathrm{T}}$. In the third phase, the increase in $\dot{V}_{\mathrm{E}}$ is caused by an increase in $\mathrm{B}_{\mathrm{f}}$ only, and by the end of this phase, there can be a fall in $\mathrm{V}_{\mathrm{T}}$. Different methods have been suggested to describe this relationship like the plateau of $\mathrm{V}_{\mathrm{T}}$ and its inflection point [14], $\mathrm{V}_{\mathrm{T} \max }$ and $\mathrm{V}_{\mathrm{T}}$ at a $\dot{\mathrm{V}}_{\mathrm{E}}$ of $30 \mathrm{~L} / \mathrm{min}$ [15], $\mathrm{V}_{\mathrm{T}}$ at given fractions of $\dot{\mathrm{V}}_{\text {Epeak }}$ [16] and the Hey plot [17]. We have found that the $\dot{V}_{E}-V_{T}$ relationship can be satisfactorily described by a quadratic model in COPD patients exercising on treadmill [18]. A quadratic model includes all available data from the exercise test. However, longitudinal changes in the breathing pattern as described by this method have not been examined.

The aims of the present study were to examine changes in exercise and ventilatory capacity and breathing pattern over four years in COPD patients, and to examine the relationship with variables that potentially contribute to explain the changes. We hypothesized that $\dot{\mathrm{V}} \mathrm{O}_{2 \text { peak }}$ and $\dot{\mathrm{V}}_{\text {Epeak }}$ would deteriorate during the observation period, that breathing pattern would be shallower with a lower $\mathrm{V}_{\text {Tmax }}$, and that the changes were related to lung hyperinflation and airway obstruction.

\section{Methods \\ Subjects}

The current study included 63 patients from the Bergen COPD Cohort Study (BCCS) who performed two cardiopulmonary exercise tests (CPETs) with an average follow-up time of 4.5 years (range 3-6 years). The BCCS was a three year follow-up study (2006-2010) and inclusion and exclusion criteria have been previously published [19]. Summarised, all patients had a smoking history of $\geq 10$ pack-years, a post- bronchodilation $\mathrm{FEV}_{1}$ to forced vital capacity (FVC) ratio $<0.7$ and a postbronchodilator $\mathrm{FEV}_{1}<80 \%$ of predicted value according to Norwegian reference values [20]. All subjects in BCCS were informed of the opportunity to participate in pulmonary rehabilitation but were not otherwise actively selected or recruited for rehabilitation. There were no restrictions to treatment in the study period.
A total of 89 patients were enrolled to a 7- week pulmonary rehabilitation program, including a total of 17 sessions, during the first two years of follow-up in 2006-2008. The first CPET was performed at start of the program. The patients were invited to a second CPET in 2011/2012. At that time 26 of the 89 patients were deceased or disabled. The 63 included patients had clinically stable COPD in stages II-IV according to the Global Initiative for Chronic Obstructive Lung Disease (GOLD) (GOLD 2007) [21] and age between 44-75 years. Exclusion criteria for exercise testing were major cardiovascular disorders, a partial pressure of oxygen in arterial blood less than $8 \mathrm{kPa}$ at rest, or exacerbations that required medical treatment during the last four weeks prior to testing.

\section{Ethics}

The Western Norway Regional Research Ethics Committee approved the study. Participation in the study was voluntary. Written and oral information was given and written consent was obtained prior to inclusion.

\section{Spirometry}

Spirometry was conducted on a Viasys Masterscope (Viasys, Hoechberg, Germany) before the CPETs according to the ATS/ERS Standardization of Lung Function Testing [22]. $\mathrm{FEV}_{1}$ and FVC were taken as the highest values from at least three satisfactory expiratory manoeuvers. The spirometer was calibrated before each test with a 3-L calibration syringe. The changes in $\mathrm{FEV}_{1}$ $\left(\triangle \mathrm{FEV}_{1}\right)$ and $\mathrm{FVC}(\triangle \mathrm{FVC})$ were calculated as $\mathrm{FEV}_{1}$ or $\mathrm{FVC}$ at CPET2 minus $\mathrm{FEV}_{1}$ or FVC at CPET1.

\section{Cardiopulmonary exercise test}

The patients completed two incremental CPETs to their symptom-limited maximum on a treadmill (Woodway, model: PPS 55 med Weiss, Weil am Rhein, Germany). The exercise protocol was a modified Bruce protocol $[23,24]$. The test started with rest in the standing position for $2 \mathrm{~min}$. The warm-up phase lasted for $1 \mathrm{~min}$ with a walking speed of $1.5 \mathrm{~km} \mathrm{~h}^{-1}$. The protocol has 20 stages, all lasting for one minute. The first stage was at $1.5 \mathrm{~km} / \mathrm{h}$ with an inclination of $0 \%$. In stage 2 , the speed was the same as in stage 1 with an inclination of $5 \%$. From stage $3-5$, the speed increased with $0.6 \mathrm{~km} / \mathrm{h}$ and the inclination was 9,10 and $11 \%$, respectively. From stage $6-13$, the speed increased with $0.6-0.7 \mathrm{~km} / \mathrm{h}$ and the inclination with $1 \%$. From stage 13-14, the speed increased with $0.4 \mathrm{~km} / \mathrm{h}$, and the inclination increased with $1 \%$. Finally, from stage $15-20$, the speed was increasing with $1 \mathrm{~km} / \mathrm{h}$ each minute and the inclination was the same as in stage 14. The warm-up was not counted into the exercise time. 
Blood pressure, electrocardiography (GE healthcare, Cardio Soft EKG, Freiburg, Germany) and pulse oximetry were monitored at rest, continuously during the test and for 3 min into the recovery phase. A tight-fitting oronasal mask was adjusted to each patient and checked for leaks before starting the exercise. The integrated exercise testing system (Care Fusion, $V_{\max }$ Spectra 229, Hochberg, Germany) was calibrated every morning and immediately before each test. The $\mathrm{V}_{\mathrm{T}}, \mathrm{B}_{\mathrm{f}}$, oxygen uptake $\left(\dot{\mathrm{V}}_{2}\right)$, carbon dioxide output $\left(\dot{\mathrm{V} C \mathrm{O}_{2}}\right)$, and heart rate $(\mathrm{HR})$ were measured on a breath by breath basis and averaged over $20 \mathrm{~s}$ intervals. $\dot{V}_{\mathrm{E}}$ and $\mathrm{V}_{\mathrm{T}}$ were corrected to the body temperature pressure saturated (BTPS) condition, and $\dot{\mathrm{VO}}{ }_{2}$ and $\dot{\mathrm{V} C O} 2$ to the standard temperature pressure dry (STPD) condition.

The patients graded their level of dyspnea and leg discomfort by Borg CR10 Scale [25]. In order to measure dynamic hyperinflation during exercise, serial measurements of inspiratory capacity (IC) were performed [5]. Measurements were taken at rest, every second minute during exercise and at peak exercise. The change in IC $(\triangle \mathrm{IC})$ during each of the CPETs was calculated as IC at rest minus IC at peak exercise. The change in dynamic hyperinflation between the CPETs $\left(\Delta \mathrm{IC} C_{\text {dynamic }}\right)$ was calculated as $\triangle \mathrm{IC}$ at CPET2 minus $\triangle \mathrm{IC}$ at CPET1. The difference in IC at rest $\left(\Delta \mathrm{IC}_{\text {rest }}\right)$ was calculated as IC at rest at CPET2 minus IC at rest at CPET1. The differences in $\dot{\mathrm{V}} \mathrm{O}_{2 \text { peak }}\left(\Delta \dot{\mathrm{V}} \mathrm{O}_{2 \text { peak }}\right)$ and $\dot{\mathrm{V}}_{\text {Epeak }}\left(\Delta \dot{\mathrm{V}}_{\text {Epeak }}\right)$ were calculated in the same way. Inspiratory reserve volume (IRV) was calculated for each of the two CPETs as the difference between IC at the end of the test minus the maximal $V_{T}$. The difference in IRV $(\Delta I R V)$ was calculated as IRV at CPET2 minus IRV at CPET1. The estimated MVV was calculated as $\mathrm{FEV}_{1} \times 35$ [26].

Self-reported physical activity was recorded at baseline and after one and three years in the BCCS [27]. Two questions were related to spare time physical activity, one for strenuous and one for light physical activity. The delineation between strenuous and light was whether the activity resulted in breathlessness and sweating or not. The response categories were none, less than $1 \mathrm{~h}$ per week, 1-2 h per week and three or more hours per week. These questions are previously validated $[28,29]$. Data on exacerbations and smoking habits were recorded at the time for the CPETs.

\section{Statistical analyses}

Descriptive statistics were used to characterize the study population (mean, standard deviation (SD), median and percent). Independent samples t-tests for continuous variables and Pearson chi square- tests for categorical variables were used to compare patients' characteristics and CPET responses to patients who only performed one CPET with those that completed both. Paired samples t-tests were used to analyze the longitudinal change in pulmonary function, exercise capacity and breathing pattern in the patients who completed both CPETs. Pearson correlation coefficient was used to calculate the linear relationship between the yearly change in $\dot{\mathrm{V}} \mathrm{O}_{2 \text { peak }}$ and $\mathrm{FEV}_{1}$. The relationships between $\Delta \dot{\mathrm{V}} \mathrm{O}_{2 \text { peak }}$ or $\Delta \dot{\mathrm{V}}_{\text {Epeak }}$ and potential explanatory variables were analysed by bivariate (unadjusted) and multivariate (adjusted) linear regression analyses. Investigated variables were age, sex, height, baseline $\dot{\mathrm{V}} \mathrm{O}_{2 \text { peak }}$ or baseline $\dot{\mathrm{V}}_{\text {Epeak }}$, smoking during follow-up, $\triangle \mathrm{FEV}_{1}, \Delta \mathrm{FVC}$, $\Delta$ weight, $\Delta \mathrm{IC}_{\text {rest }}, \Delta \mathrm{IC}_{\text {dynamic }}$, self-reported physical activity, exacerbations and time between the tests. $\triangle \mathrm{FVC}$ was not included in the multivariate regression analysis, because it is an intermediary variable with $\triangle \mathrm{FEV}_{1}$ and the outcome variable.

A quadratic model $\left(\mathrm{V}_{\mathrm{T}}=\mathrm{a}+\mathrm{b} \cdot \dot{\mathrm{V}}_{\mathrm{E}}+\mathrm{c} \cdot \dot{\mathrm{V}}_{\mathrm{E}}^{2}\right)$ was used to describe the relationship between $\dot{\mathrm{V}}_{\mathrm{E}}$ and $\mathrm{V}_{\mathrm{T}}$ during incremental exercise. The goodness-of-fit for the individual patient specific regression analysis was evaluated by the adjusted coefficient of determination (adjusted $R^{2}$ ) and the $\mathrm{F}$ statistic. For the latter a $p$-value $<0.05$ was required for inclusion of the patient in further analysis. These analyses were done for each individual patient in CPET1 and CPET2.

The mean values for the curve parameters the constant (intercept) (a), the linear coefficient (slope) (b) and the quadratic coefficient (curvature) (c) were calculated. $\mathrm{V}_{\mathrm{Tmax}}$ was calculated from the individual quadratic relationships, and was the point where the first derivative of the quadratic equation was zero. The mean change (CPET2 minus CPET1) in the curve parameters and the change in $\mathrm{V}_{\text {Tmax }}\left(\Delta \mathrm{V}_{\text {Tmax }}\right)$ were analysed by bivariate and multivariate linear regression analysis with age, sex, height, $\Delta$ weight, $\Delta \mathrm{FEV}_{1}, \Delta \mathrm{IRV}, \Delta \mathrm{IC}_{\text {rest }}$, and $\Delta \mathrm{IC}_{\text {dynamic }}$ as explanatory variables.

Estimated regression coefficients are presented with $95 \%$ confidence intervals and $p$-values. The significance level was set at 0.05 . The data analyses were performed using IBM SPSS Statistics 21 (SPSS Inc. Chicago, Illinois, USA).

\section{Results}

The baseline characteristics of the study population and the peak responses to the incremental exercise test at baseline are shown in Table 1 . The patients' mean age (SD) was 61 (6) years, $56 \%$ were males and mean FEV 1 in percent of predicted values was 51 (14) \%. The 26 patients who only performed the first CPET were older, had lower lung function and lower peak responses at the CPET (Table 1).

Forty patients (63\%) remained in the same GOLD stage during the follow-up, while eight (13\%) patients had improved GOLD stage, six from stage III to II and two from stage IV to III, respectively. Fifteen patients 
Table 1 Baseline characteristics of the study sample $(n=63)$ compared with patients only assessed at baseline $(n=26)$

\begin{tabular}{|c|c|c|c|}
\hline Variables & $\begin{array}{l}\text { Completed one CPET } \\
n=26\end{array}$ & $\begin{array}{l}\text { Completed two CPETs } \\
n=63\end{array}$ & $\begin{array}{l}\text { Group diff. } \\
p \text {-value }\end{array}$ \\
\hline Sex, male/female n (\%) & $18 / 8(69 / 31)$ & $35 / 28(56 / 44)$ & 0.232 \\
\hline Age (years) & $64.4 \pm 5.8$ & $61.2 \pm 6.2$ & 0.028 \\
\hline Smoking status n (\%) & & & 0.471 \\
\hline Current & $9(35)$ & $27(43)$ & \\
\hline Former & $17(65)$ & $36(57)$ & \\
\hline Pack years & $38 \pm 19$ & $43 \pm 26$ & 0.380 \\
\hline Height (m) & $1.72 \pm 0.1$ & $1.71 \pm 0.1$ & 0.540 \\
\hline Weight (kg) & $72.8 \pm 20.7$ & $76.4 \pm 17.5$ & 0.406 \\
\hline BMI (mean, $\mathrm{kg} \cdot \mathrm{m}^{-2}$ ) & $24.4 \pm 5.4$ & $26.3 \pm 4.9$ & 0.108 \\
\hline $\mathrm{FEV}_{1}(\%$ pred.) & $38.2 \pm 11.4$ & $51.4 \pm 13.5$ & $<0.001$ \\
\hline FVC (\% pred.) & $83.5 \pm 20.6$ & $90.1 \pm 17.2$ & 0.120 \\
\hline $\mathrm{FEV}_{1} / \mathrm{FVC}(\%)$ & $36.4 \pm 7.6$ & $46.4 \pm 10.8$ & $<0.001$ \\
\hline $\mathrm{IC}_{\text {rest }}(\mathrm{L})$ & $1.91 \pm 0.50$ & $2.36 \pm 0.75$ & 0.006 \\
\hline$\Delta \mathrm{IC}(\mathrm{L})$ & $0.30 \pm 0.28$ & $0.41 \pm 0.40$ & 0.232 \\
\hline GOLD category & & & 0.001 \\
\hline || n (\%) & $5(19)$ & $34(54)$ & \\
\hline III n (\%) & $14(54)$ & $26(41)$ & \\
\hline IV n (\%) & $7(27)$ & $3(5)$ & \\
\hline mMRC dyspnea grade & $1.6 \pm 0.9$ & $1.3 \pm 1.2$ & 0.316 \\
\hline Experienced $^{1} \geq 2$ exacerbations last year & & & 0.402 \\
\hline No n (\%) & $18(69)$ & $49(78)$ & \\
\hline Yes n (\%) & $8(31)$ & $14(22)$ & \\
\hline Exercise time (min) & $4.78 \pm 1.66$ & $6.44 \pm 1.88$ & $<0.001$ \\
\hline$\dot{\mathrm{V}} \mathrm{O}_{2 \text { peak }}\left(\mathrm{L} \cdot \mathrm{min}^{-1}\right)$ & $1.09 \pm 0.31$ & $1.57 \pm 0.57$ & $<0.001$ \\
\hline$\dot{\mathrm{V}} \mathrm{CO}_{2 \text { peak }}\left(\mathrm{L} \cdot \mathrm{min}^{-1}\right)$ & $1.08 \pm 0.38$ & $1.65 \pm 0.69$ & $<0.001$ \\
\hline$\dot{V}_{\text {Epeak }}\left(L \cdot \min ^{-1}\right)$ & $40.2 \pm 13.3$ & $53.8 \pm 19.2$ & $<0.001$ \\
\hline$H R_{\text {peak }}(b p m)$ & $125 \pm 21$ & $138 \pm 20$ & 0.009 \\
\hline RER & $0.98 \pm 0.12$ & $1.03 \pm 0.12$ & 0.047 \\
\hline Dyspnea (Borg Scale) & $8.6 \pm 1.7$ & $9.0 \pm 1.6$ & 0.481 \\
\hline Leg discomfort (Borg Scale) & $5.5 \pm 3.4$ & $5.6 \pm 2.8$ & 0.905 \\
\hline $\mathrm{SpO}_{2}$ start (\%) & $96.8 \pm 3.4$ & $97.1 \pm 2.2$ & 0.546 \\
\hline $\mathrm{SpO}_{2}$ end (\%) & $89.9 \pm 6.3$ & $92.8 \pm 5.0$ & 0.024 \\
\hline
\end{tabular}

Data are presented as mean \pm SD, unless otherwise stated. Chi square for categorical variables and independent $t$-test for continuous variables. CPET:

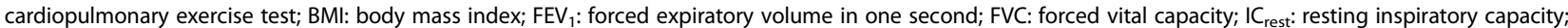
$\triangle \mathrm{IC}$ : inspiratory capacity at rest minus IC at the end of the test; GOLD: Global Initiative for Chronic Obstructive Lung Disease; mMRC: modified Medical Research Council. $\dot{V} O_{2 \text { peak: }}$ peak oxygen uptake per minute; $\mathrm{V} \mathrm{CO}_{2 \text { peak: }}$ peak carbon dioxide production per minute $\dot{\mathrm{V}}_{\text {Epeak: }}$ peak minute ventilation per minute; $\mathrm{HR}_{\text {peak: }}$ peak heart rate; RER: respiratory exchange ratio; $\mathrm{SpO}_{2}$ : oxygen saturation

${ }^{1}$ Exacerbations requiring either hospitalization with oral antibiotics or oral steroids

(24\%) had changed to a worse GOLD stage, eight from stage II to III and seven from stage III to IV.

\section{Longitudinal changes in exercise and ventilatory capacity} $\mathrm{FEV}_{1}, \mathrm{FVC}, \dot{\mathrm{V}} \mathrm{O}_{2 \text { peak }}$ and $\dot{\mathrm{V}}_{\text {Epeak }}$ decreased significantly during the follow-up period (Table 2), while the exercise time on treadmill remained constant. The Borg dyspnea score was not significantly different. The mean (SD) decline in $\mathrm{FEV}_{1}$ was $34(66) \mathrm{mL} \cdot \mathrm{yr}^{-1},(p<0.001)$ and in $\dot{\mathrm{VO}}{ }_{2 \text { peak, }} 50(68) \mathrm{mL} \cdot \mathrm{min}^{-1} \cdot \mathrm{yr}^{-1}(p<0.001)$. The decline in $\mathrm{VO}_{2 \text { peak }}$ and $\mathrm{FEV}_{1}$ during the observation period correlated moderately $(r=0.43, p<0.001)$ (Fig. 1).

The reduction in $\dot{\mathrm{V}} \mathrm{O}_{2 \text { peak }}$ was larger in subjects with a higher baseline $\dot{\mathrm{V}} \mathrm{O}_{2 \text { peak }}(\mathrm{p}<0.001)$ and with a larger reduction in $\Delta \mathrm{IC}_{\text {rest }}(p=0.002)$ (Table 3$)$. Furthermore age $(p=0.023), \Delta \operatorname{FEV}_{1}(p=0.031)$ and smoking during 
Table 2 Pulmonary function and peak responses to cardiopulmonary exercise tests at baseline and 4.5 years apart

\begin{tabular}{|c|c|c|c|c|}
\hline Variables & $\begin{array}{l}\text { CPET } 1 \\
n=63\end{array}$ & $\begin{array}{l}\text { CPET } 2 \\
n=63\end{array}$ & $\begin{array}{l}\text { Change CPET2 } \\
\text { minus CPET1 }\end{array}$ & $p$-value \\
\hline Sex, male/female (n) & $35 / 28$ & & & \\
\hline Weight (kg) & $76.4 \pm 17.5$ & $76.0 \pm 17.4$ & $-0.4 \pm 5.2$ & 0.599 \\
\hline $\mathrm{FEV}_{1}(\mathrm{~L})$ & $1.60 \pm 0.53$ & $1.46 \pm 0.57$ & $-0.15 \pm 0.28$ & $<0.001$ \\
\hline $\mathrm{FEV}_{1}$ (\% pred) & $51.4 \pm 13.5$ & $48.0 \pm 14.8$ & $-3.4 \pm 9.5$ & 0.006 \\
\hline FVC (L) & $3.47 \pm 0.89$ & $3.14 \pm 0.86$ & $-0.34 \pm 0.50$ & $<0.001$ \\
\hline FVC (\% pred) & $90.1 \pm 17.2$ & $82.8 \pm 15.3$ & $-7.4 \pm 14.7$ & $<0.001$ \\
\hline $\mathrm{FEV}_{1} / \mathrm{FVC}(\%)$ & $46.4 \pm 10.8$ & $46.0 \pm 11.2$ & $-0.4 \pm 0.05$ & 0.549 \\
\hline Exercise time (min) & $6.44 \pm 1.88$ & $6.44 \pm 2.18$ & $-0.01 \pm 1.61$ & 0.980 \\
\hline$\dot{\mathrm{V}} \mathrm{O}_{2 \text { peak }}\left(\mathrm{L} \cdot \mathrm{min}^{-1}\right)$ & $1.57 \pm 0.57$ & $1.36 \pm 0.54$ & $-0.22 \pm 0.29$ & $<0.001$ \\
\hline$\dot{\mathrm{V}} \mathrm{CO}_{\text {2peak }}\left(\mathrm{L} \cdot \mathrm{min}^{-1}\right)$ & $1.65 \pm 0.69$ & $1.34 \pm 0.67$ & $-0.31 \pm 0.37$ & $<0.001$ \\
\hline$\dot{V}_{\text {Epeak }} / \mathrm{MW}$ & $0.98 \pm 0.22$ & $0.94 \pm 0.19$ & $-0.03 \pm 0.20$ & 0.196 \\
\hline$\dot{V}_{\text {Epeak }}\left(\mathrm{L} \cdot \mathrm{min}^{-1}\right)$ & $53.8 \pm 19.2$ & $47.3 \pm 19.6$ & $-6.5 \pm 11.6$ & $<0.001$ \\
\hline $\mathrm{V}_{\text {Tmax }}(\mathrm{L})^{2}$ & $1.71 \pm 0.51$ & $1.48 \pm 0.43$ & $-0.23 \pm 0.41$ & $<0.001$ \\
\hline$H R_{\text {peak }}(b p m)$ & $138 \pm 20$ & $133 \pm 19$ & $-5 \pm 14$ & 0.004 \\
\hline RER & $1.03 \pm 0.12$ & $0.96 \pm 0.14$ & $-0.08 \pm 0.11$ & $<0.001$ \\
\hline Dyspnea (Borg Scale) & $9.0 \pm 1.6$ & $8.7 \pm 1.6$ & $-0.3 \pm 1.8$ & 0.327 \\
\hline Leg discomfort (Borg Scale) & $5.6 \pm 2.8$ & $5.9 \pm 3.0$ & $0.3 \pm 2.8$ & 0.651 \\
\hline$I C_{\text {rest }}$ & $2.36 \pm 0.75$ & $2.21 \pm 0.78$ & $-0.13 \pm 0.48$ & 0.039 \\
\hline$\Delta \mathrm{IC}(\mathrm{L})$ & $0.41 \pm 0.40$ & $0.46 \pm 0.33$ & $0.05 \pm 0.38$ & 0.208 \\
\hline $\mathrm{IRV}(\mathrm{L})$ & $0.44 \pm 0.37$ & $0.38 \pm 0.26$ & $-0.05 \pm 0.34$ & 0.233 \\
\hline $\mathrm{MW}\left(\mathrm{L} \cdot \mathrm{min}^{-1}\right)$ & $56.0 \pm 18.6$ & $51.0 \pm 20.1$ & $-5.1 \pm 9.8$ & $<0.001$ \\
\hline $\mathrm{SpO}_{2}$ start (\%) & $97.1 \pm 2.2$ & $95.9 \pm 2.5$ & $-1.2 \pm 3.2$ & 0.004 \\
\hline $\mathrm{SpO}_{2}$ end (\%) & $92.8 \pm 5.1$ & $89.6 \pm 5.1$ & $-3.2 \pm 4.4$ & $<0.001$ \\
\hline \multicolumn{5}{|l|}{ Curve parameters } \\
\hline Intercept $(a)^{1}$ & $-0.05(0.47)$ & $-0.18(0.44)$ & $-0.13(0.46)$ & 0.032 \\
\hline Slope $(b)^{1}$ & $0.063(0.032)$ & $0.076(0.035)$ & $0.014(0.037)$ & 0.007 \\
\hline Curvature $(c)^{1}$ & $-0.00071(0.00059)$ & $-0.00105(0.00079)$ & $-0.00036(0.00077)$ & 0.002 \\
\hline
\end{tabular}

Data are presented as mean $\pm S D$, unless otherwise stated. Independent $t$-test for continuous variables

CPET: cardiopulmonary exercise test; $\mathrm{FEV}_{1}$ : forced expiratory volume in one second; FVC: forced vital capacity; $\dot{V}_{2 \text { peak: }}$ peak oxygen uptake per minute; $\dot{\mathrm{V}} \mathrm{CO}_{2 \text { peak: }}$ : peak carbon dioxide production per minute; $\dot{\mathrm{V}}_{\text {Epeak }}$ : peak minute ventilation per minute; MVV: maximal voluntary ventilation (FEV $\left.{ }_{1} 35\right)$

$\mathrm{V}_{\text {Tmax }}$ : maximal tidal volume; $\mathrm{HR}_{\text {peak }}$ : peak heart rate; RER: respiratory exchange ratio; $\mathrm{IC}_{\text {rest }}$ : resting inspiratory capacity; $\triangle \mathrm{IC}$ : IC at rest minus IC at the end of the test; IRV: inspiratory reserve volume; $\mathrm{SpO}_{2}$ : oxygen saturation

${ }^{1}$ The relationship between ventilation $\left(\dot{V}_{E}\right)$ and tidal volume $\left(V_{T}\right)$ was described by a quadratic model $\left(V_{T}=a+b \cdot \dot{V}_{E}+c \cdot \dot{V}_{E}^{2}\right) .{ }^{2} V_{T m a x}$ was calculated from the individual quadratic relationships, and was the point where the first derivative of the quadratic equation was zero

follow-up $(p=0.021)$ were found to be related to the change in $\dot{\mathrm{V}} \mathrm{O}_{2 \text { peak. }} \Delta \dot{\mathrm{V}}_{\text {Epeak }}$ was related to $\Delta \mathrm{IC}_{\text {rest }}$ $(p=0.005), \quad \Delta \mathrm{FEV}_{1} \quad(p=0.023)$ and baseline $\dot{\mathrm{V}}_{\text {Epeak }}$ $(p=0.002)$ (Table 3). Gender was not associated with the reduction in $\dot{\mathrm{V}} \mathrm{O}_{2 \text { peak }}$ or $\dot{\mathrm{V}}_{\text {Epeak }}$.

Self-reported physical activity during follow-up as reported in Bergen COPD Cohort Study and exacerbations were not related to the longitudinal changes in $\dot{\mathrm{V}} \mathrm{O}_{2 \text { peak }}$ or $\dot{\mathrm{V}}_{\text {Epeak }}$ (Table 3).

\section{Longitudinal changes in breathing pattern}

The quadratic model described the relationship between $\dot{\mathrm{V}}_{\mathrm{E}}$ and $\mathrm{V}_{\mathrm{T}}$ in 61 of 63 patients at CPET1 and at 59 of 63 patients in CPET2. In these subjects the p-value of the F-statistics for the quadratic model was $<0.05$ and the $R^{2}$ ranged from 0.35 to 0.99 (median 0.90) at CPET1, and from 0.40 to 0.98 (median 0.90) at CPET2. A random set of three individual responses from CPET1 and CPET2 are shown in Fig. 2. For the six excluded patients the goodness of fit was not statistically significant and the exercise time was short with few observations. The means of the estimated constant (a), the linear coefficient (b) and the quadratic coefficient (c) changed significantly from CPET1 to CPET2 (Table 2). The linear coefficient (b) increased $(p=0.007)$ and the quadratic coefficient (c) decreased $(p=0.002)$. The changes in the 


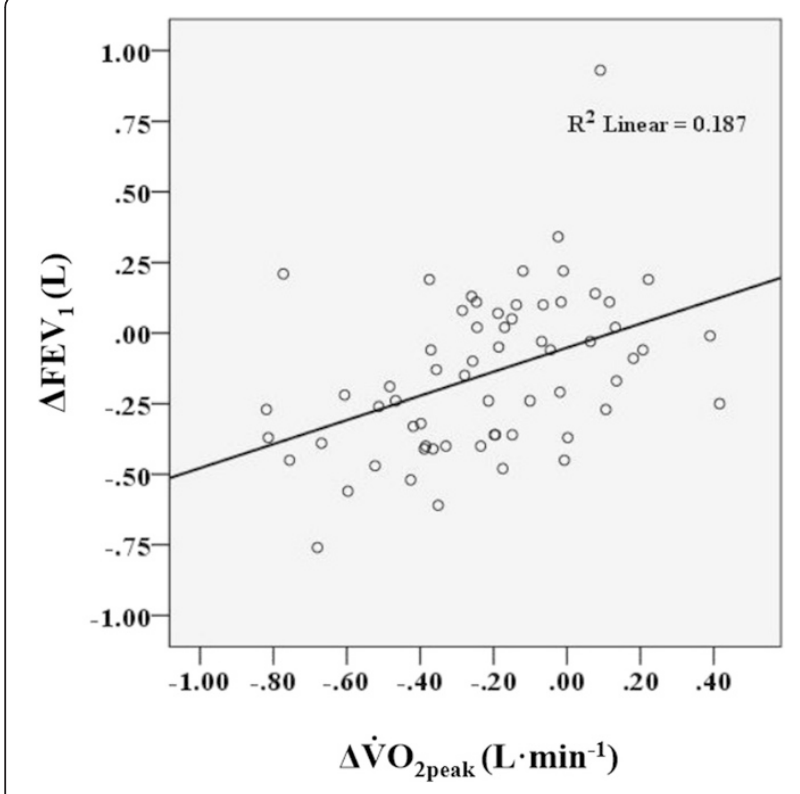

Fig. 1 The relationship between change in $\dot{\mathrm{V}}_{2 \text { peak }}$ and change in $\mathrm{FEV}_{1}$ between the two cardiopulmonary exercise tests (CPET). $\dot{V} \mathrm{O}_{2 \text { peak }}$ : Peak oxygen uptake. $\Delta \dot{V} \mathrm{O}_{2 \text { peak: }}: \dot{\mathrm{V}} \mathrm{O}_{2 \text { peak }}$ at $\mathrm{CPET} 2$ minus $\dot{V} \mathrm{~V}_{2 \text { peak }}$ at CPET1. FEV 1 : Forced expiratory volume in $1 \mathrm{sec} . \Delta \mathrm{FEV}_{1}: \mathrm{FEV}_{1}$ at CPET2 minus FEV ${ }_{1}$ at CPET1. R2: The coefficient of determination

curve parameters were all related to $\Delta \mathrm{FEV}_{1}$, but not to the other possibly explanatory variables (Table 4). Maximal $\mathrm{V}_{\mathrm{T}}$ was achieved at a lower $\dot{\mathrm{V}}_{\mathrm{E}}$.

The $\mathrm{V}_{\text {Tmax }}$ decreased significantly from CPET1 to CPET2 $(p<0.001)$ (Table 2). In the multivariate linear regression analysis, $\Delta \mathrm{V}_{\mathrm{Tmax}}$ was significantly related to the reduction in $\mathrm{FEV}_{1}(\mathrm{~B}=0.429, \mathrm{CI}: 0.106-0.751, p<0.010)$, the reduction in $\mathrm{IC}_{\text {rest }}(\mathrm{B}=0.325, \mathrm{CI}: 0.053-0.596, p<0.020)$ and the baseline $\mathrm{V}_{\text {Tmax }}(\mathrm{B}=-0.471, \mathrm{CI}:-0.662--0.281, p<0.01)$.

\section{Discussion}

The major findings of this study of a group of COPD patients who were followed over a mean time of 4.5 years were a reduction in $\dot{\mathrm{VO}}_{2 \text { peak }}$ and $\dot{\mathrm{V}}_{\text {Epeak }}$ which were related to a decrease in resting $\mathrm{IC}$ and $\mathrm{FEV}_{1}$, and persistent smoking during the observation period. The breathing pattern changed towards a lower $\mathrm{V}_{\text {Tmax }}$ and a lower $\mathrm{V}_{\mathrm{T}}$ at a given $\dot{\mathrm{V}}_{\mathrm{E}}$. The reduction in $\mathrm{FEV}_{1}$ was related to the changes in the curve parameters describing the breathing pattern.

The mean reduction in $\dot{\mathrm{V}} \mathrm{O}_{2 \text { peak }}$ was $50 \quad(\mathrm{SD}=68)$ $\mathrm{mL} \cdot \mathrm{min}^{-1} \cdot \mathrm{yr}^{-1}$, which was slightly higher than the decline in $\dot{\mathrm{VO}}_{2 \text { peak }}$ of $32 \mathrm{~mL} \cdot \mathrm{min}^{-1} \cdot \mathrm{yr}^{-1}$ in male COPD patients reported by Oga et al. [12]. In our study, both genders were included, but the reduction in $\dot{\mathrm{VO}}_{2 \text { peak }}$ or $\dot{\mathrm{V}}_{\text {Epeak }}$ was not associated with gender. The reduction in resting IC and $\mathrm{FEV}_{1}$, baseline $\dot{\mathrm{VO}}_{2 \text { peak }}$, smoking during follow-up and age were all found to be related to the change in $\dot{\mathrm{VO}}_{2 \text { peak. }}$. As shown in Fig. 1 the association between the changes in $\mathrm{FEV}_{1}$ and $\dot{\mathrm{V}} \mathrm{O}_{2 \text { peak }}$ was rather weak with large interindividual variation. The strongest associations were found for resting IC and baseline $\dot{\mathrm{VO}}_{2 \text { peak. }}$ Total lung capacity (TLC) was not measured, and we are not aware of any studies having described the longitudinal change in TLC in COPD patients. Based on data from cross-sectional studies of COPD patients, TLC is expected to remain unaltered or slightly increased [30-32]. Thus, there is a possibility that the increase in static hyperinflation as estimated by resting IC is underestimated. There were no significant differences in dynamic hyperinflation between CPET1 and CPET2. Without knowledge about TLC changes in dynamic hyperinflation may have been obscured. Theoretically, dynamic hyperinflation is likely important since it is associated with increased work of breathing and dyspnea [1, 33].

The exercise time was the same at the two CPETs, which can indicate better working economy, even though $\dot{\mathrm{VO}}_{2 \text { peak }}$ and lung function decreased significantly. The respiratory exchange ratio and $\dot{\mathrm{V}} \mathrm{CO}_{2 \text { peak }}$ were lower at the second CPET, whereas maximal Borg dyspnea score was not significantly different at the two CPETs. These observations are consistent with previous studies showing that laboratory-based constant work rate tests can be more sensitive demonstrating improvements after interventions than $\dot{\mathrm{VO}}_{2 \text { peak }}[11,34]$.

We described the breathing pattern in the individual patient by a quadratic relationship between $\dot{\mathrm{V}}_{\mathrm{E}}$ and $\mathrm{V}_{\mathrm{T}}$. The relationship could be satisfactorily described by the model in the majority of the subjects, and the model accounts for all observations throughout the exercise test. The limitations with other methods [14-17] are that all observed data from the exercise test are not included in the analyses. O'Donnell et al. [14] has described the relationship between $\dot{V}_{E}$ and $V_{T}$ during exercise as linear until an inflection point. After this point, further increase in $\dot{\mathrm{V}}_{\mathrm{E}}$ is accomplished by an increase in $\mathrm{B}_{\mathrm{f}}$. The inflection point is determined "by eye" by two or three persons independently of each other $[14,17]$. When we examined our exercise data, it was not obvious to see where an inflection point could occur. In a quadratic model, which is analysed mathematically, the curve parameter $\mathrm{c}$ in the equation will be related to a "perceived" inflection point as it describes the "sharpness" of the curvature, and the $V_{\text {Tmax }}$ can be calculated by derivation of the equation. By using this method determinations of the curve parameters will not be influenced by intra-and/or inter observer reliability. Another consideration is that during an incremental exercise test, there will be a gradual transition between the phases as described by Gallagher [13], and determining a cut-off point where the change from one phase to the other takes place, is not exactly defined. The changes in 
Table $\mathbf{3}$ The relationships between changes in peak oxygen uptake and peak minute ventilation and explanatory variables

\begin{tabular}{|c|c|c|c|c|c|c|}
\hline \multirow[t]{2}{*}{ Variable } & \multicolumn{2}{|c|}{ Unadjusted } & \multicolumn{3}{|c|}{ Adjusted } & \multirow[t]{2}{*}{$p$-value } \\
\hline & $B$ & $p$-value & $\mathrm{B}$ & St. $B^{*}$ & $95 \% \mathrm{Cl}$ & \\
\hline \multicolumn{7}{|l|}{$\Delta \dot{\mathrm{V}} \mathrm{O}_{2 \text { peak }}\left(\mathrm{L} \cdot \mathrm{min}^{-1}\right)$} \\
\hline Age (years) & -0.006 & 0.273 & -0.011 & -0.238 & $-0.020--0.002$ & 0.023 \\
\hline Sex & -0.146 & 0.042 & 0.022 & 0.039 & $-0.110-0.155$ & 0.737 \\
\hline Height (m) & -0.652 & 0.145 & & & & \\
\hline$\dot{\mathrm{V}} \mathrm{O}_{2 \text { peak }}$ at baseline $\left(\mathrm{L} \cdot \mathrm{min}^{-1}\right)$ & -0.178 & 0.004 & -0.260 & -0.515 & $-0.379--0.141$ & $<0.001$ \\
\hline Smoking during follow-up & -0.108 & 0.144 & -0.139 & -0.240 & $-0.257--0.021$ & 0.021 \\
\hline$\Delta \mathrm{FEV}_{1}(\mathrm{~L})$ & 0.440 & $<0.001$ & 0.254 & 0.251 & $0.024-0.484$ & 0.031 \\
\hline$\Delta \mathrm{FVC}(\mathrm{L})$ & 0.271 & $<0.001$ & & & & \\
\hline$\Delta$ Weight (kg) & -0.004 & 0.604 & & & & \\
\hline$\Delta \mathrm{I} \mathrm{C}_{\text {rest }}(\mathrm{L})$ & 0.317 & $<0.001$ & 0.294 & 0.492 & $0.110-0.478$ & 0.002 \\
\hline$\Delta \mathrm{I} \mathrm{C}_{\text {dynamic }}(\mathrm{L})$ & 0.202 & 0.037 & -0.105 & -0.140 & $-0.315-0.105$ & 0.320 \\
\hline Strenuous physical activity & 0.020 & 0.593 & & & & \\
\hline Light physical activity & 0.079 & 0.131 & & & & \\
\hline Exacerbations & -0.100 & 0.166 & & & & \\
\hline \multirow[t]{2}{*}{ Time between CPET1 and CPET2 } & 0.005 & 0.907 & & & & \\
\hline & & & & & & $R^{2}=0.567$ \\
\hline \multicolumn{7}{|l|}{$\Delta \dot{V}_{\text {Epeak }}\left(L \cdot \min ^{-1}\right)$} \\
\hline Age (years) & -0.075 & 0.756 & -0.131 & -0.070 & $-0.545-0.283$ & 0.528 \\
\hline Sex & -2.484 & 0.404 & 3.180 & 0.163 & $-2.111-9.732$ & 0.203 \\
\hline Height (m) & -3.447 & 0.848 & & & & \\
\hline$\dot{V}_{\text {Epeak }}$ at baseline $\left(L \cdot \mathrm{min}^{-1}\right)$ & -0.163 & 0.032 & -0.259 & -0.422 & $-0.415--0.103$ & 0.002 \\
\hline Smoking during follow-up & -3.506 & 0.249 & & & & \\
\hline$\Delta \mathrm{FEV}_{1}(\mathrm{~L})$ & 19.220 & $<0.001$ & 11.845 & 0.285 & $1.699-21.990$ & 0.023 \\
\hline$\Delta \mathrm{FVC}(\mathrm{L})$ & 11.626 & $<0.001$ & & & & \\
\hline$\Delta$ Weight (kg) & -0.324 & 0.254 & & & & \\
\hline$\Delta \mathrm{I} \mathrm{C}_{\text {rest }}(\mathrm{L})$ & 13.030 & $<0.001$ & 12.135 & 0.497 & 3.759-20.510 & 0.005 \\
\hline$\Delta \mathrm{I} \mathrm{C}_{\text {dynamic }}(\mathrm{L})$ & 11.109 & 0.004 & -4.219 & -0.137 & $-13.748-5.310$ & 0.379 \\
\hline Strenuous physical activity & 0.984 & 0.512 & & & & \\
\hline Light physical activity & 2.241 & 0.297 & & & & \\
\hline Exacerbations & -4.775 & 0.104 & & & & \\
\hline Time between CPET1 and CPET2 & -0.299 & 0.870 & & & & \\
\hline
\end{tabular}

$95 \%$ confidence interval $(\mathrm{Cl})$ examined by linear regression in bivariate and multivariate analyses

CPET: cardiopulmonary exercise test; $\dot{\mathrm{VO}}_{2 \text { peak: }}$ peak oxygen uptake per minute; $\Delta \dot{\mathrm{VO}}_{2 \text { peak }}$ : $\dot{\mathrm{V}}_{2 \text { peak }}$ at $\mathrm{CPET}_{2}$ minus $\dot{\mathrm{VO}}_{2 \text { peak }}$ at $\mathrm{CPET}_{1}$; FEV 1 : forced expiratory volume in one second; $\triangle \mathrm{FEV}_{1}: \mathrm{FEV}_{1}$ at CPET2 minus FEV 1 at CPET1; FVC: forced vital capacity; $\triangle \mathrm{FVC}$ and $\triangle$ weight were calculated like $\triangle \mathrm{FEV} \mathrm{F}_{1}$ IC: inspiratory capacity. $\triangle \mathrm{IC}_{\text {rest }}$ was calculated as IC at rest at CPET2 minus IC at rest at CPET1. $\triangle \mathrm{IC}$ was calculated as IC at rest minus IC at the end of the test for both CPET1 and CPET2.

$\Delta \mathrm{IC}_{\text {dynamic }}$ was calculated as $\triangle \mathrm{IC}$ at CPET2 minus $\triangle \mathrm{IC}$ at CPET1; $\dot{\mathrm{V}}_{\mathrm{E}}$ : minute ventilation per minute; $\Delta \dot{\mathrm{V}}_{\mathrm{E}}$ peak: peak $\dot{\mathrm{V}}_{\mathrm{E}}$ at $\mathrm{CPET} 2$ minus peak $\dot{\mathrm{V}}_{\mathrm{E}}$ at $\mathrm{CPET} 1 ; \mathrm{R}^{2}$ : The coefficient of determination

*St.B: Standardised beta

the curve parameters describing the breathing pattern were found to be related to the change in $\mathrm{FEV}_{1}$.

The time constant for the lung is increased in COPD due to both increased resistance and compliance. Dynamic hyperinflation in response to increasing ventilatory demands is a necessary compensatory mechanism allowing complete respiratory cycles. Resistance and compliance are both related to $\mathrm{FEV}_{1}$, but we did not find any relationships between changes in breathing pattern and changes in IC or IRV after adjusting for $\mathrm{FEV}_{1}$.

\section{Study limitations}

The BCCS, which this study sample is a part of, made no restrictions to treatment in the study period, and the 


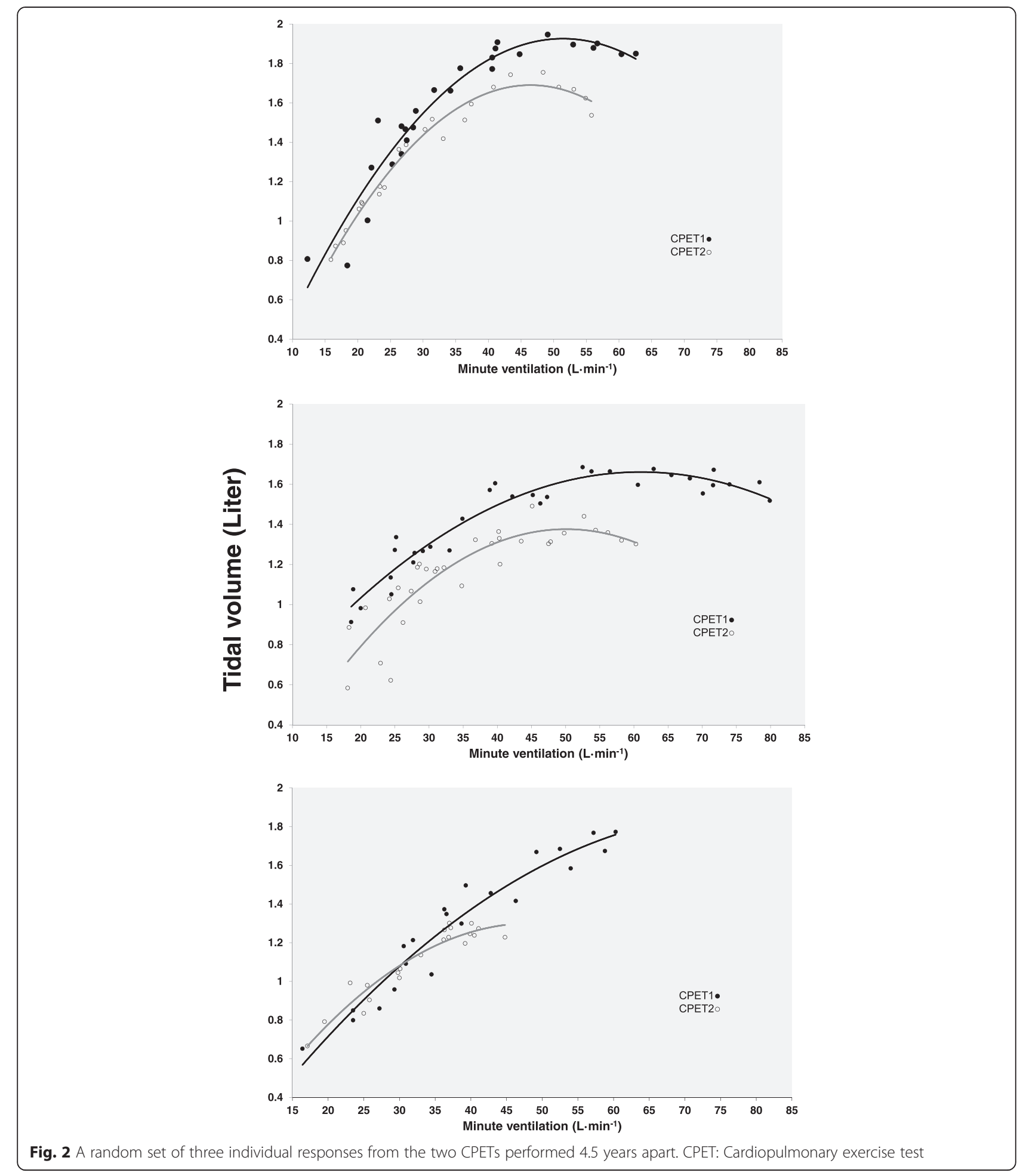

participants were free to receive medication or other treatment prescribed by their physician. Since the included patients participated in a pulmonary rehabilitation program after the first CPET, this was a selected group and the results cannot be generalized to the common COPD population. One of the major effect of pulmonary rehabilitation is to increase exercise tolerance and reduce shortness of breath, but since there was no maintenance program, the effect of the rehabilitation probably would be negligible after four years. The reduction in $\mathrm{FEV}_{1}$ in our patients was $34(\mathrm{SD}=66) \mathrm{mL} \cdot \mathrm{year}^{-1}$, which was not different from the mean rate of decline in $\mathrm{FEV}_{1}$ of $33 \mathrm{~mL} \cdot \mathrm{year}^{-1}$ in the 
Table 4 The relationships between the change in the curve parameters ${ }^{1}$ and explanatory variables (CPET2 minus CPET1)

\begin{tabular}{|c|c|c|c|c|c|c|}
\hline \multirow[b]{2}{*}{ Variable } & \multicolumn{2}{|l|}{ Unadjusted } & \multirow[b]{2}{*}{ B } & \multicolumn{3}{|c|}{ Adjusted } \\
\hline & $\bar{B}$ & $\overline{p \text {-value }}$ & & St.B* & $95 \% \mathrm{Cl}$ & $p$-value \\
\hline \multicolumn{7}{|c|}{ Intercept ${ }^{1}$ (Curve parameter a) } \\
\hline Age & 0.002 & 0.803 & -0.0003 & -0.004 & $-0.015-0.014$ & 0.966 \\
\hline Sex & -0.089 & 0.468 & -0.126 & -0.138 & $-0.312-0.060$ & 0.180 \\
\hline Height & 0.145 & 0.844 & & & & \\
\hline$a_{\text {baseline }}$ & -0.545 & $<0.001$ & -0.573 & -0.588 & $-0.769--0.376$ & $<0.001$ \\
\hline$\Delta$ weight & -0.002 & 0.881 & & & & \\
\hline$\Delta \mathrm{FEV}_{1}$ & 0.601 & 0.005 & 0.762 & 0.461 & $0.376-1.149$ & $<0.001$ \\
\hline$\Delta \mathrm{FVC}$ & 0.427 & 0.001 & & & & \\
\hline$\Delta \mathrm{I} \mathrm{C}_{\text {rest }}(\mathrm{L})$ & 0.116 & 0.374 & -0.052 & -0.053 & $-0.365-0.262$ & 0.743 \\
\hline$\Delta \mathrm{I} \mathrm{C}_{\text {dynamic }}(\mathrm{L})$ & -0.025 & 0.882 & -0.203 & -0.166 & $-0.561-0.156$ & 0.262 \\
\hline \multirow[t]{2}{*}{$\Delta \mathrm{RV}$} & -0.147 & 0.416 & & & & \\
\hline & & & & & & $R^{2}=0.507$ \\
\hline \multicolumn{7}{|c|}{ Slope ${ }^{1}$ (Curve parameter $b$ ) } \\
\hline Age & -0.0003 & 0.725 & 0.00003 & 0.006 & $-0.001-0.001$ & 0.959 \\
\hline Sex & 0.002 & 0.860 & 0.012 & 0.159 & $-0.005-0.029$ & 0.177 \\
\hline Height & -0.059 & 0.311 & & & & \\
\hline$b_{\text {baseline }}$ & -0.568 & $<0.001$ & -0.588 & -0.510 & $-0.854--0.322$ & $<0.001$ \\
\hline$\Delta$ weight & 0.002 & 0.862 & & & & \\
\hline$\Delta \mathrm{FEV}_{1}$ & -0.046 & 0.009 & -0.050 & -0.373 & $-0.085--0.015$ & 0.006 \\
\hline$\Delta \mathrm{FVC}$ & -0.032 & 0.003 & & & & \\
\hline$\Delta \mathrm{I} \mathrm{C}_{\text {rest }}(\mathrm{L})$ & -0.008 & 0.429 & -0.001 & -0.008 & $-0.029-0.028$ & 0.963 \\
\hline$\Delta \mathrm{I}_{\text {dynamic }}(\mathrm{L})$ & 0.005 & 0.734 & 0.018 & 0.183 & $-0.014-0.050$ & 0.265 \\
\hline$\Delta \mathrm{RV}$ & -0.023 & 0.119 & & & & $R^{2}=0.393$ \\
\hline \multicolumn{7}{|c|}{ Curvature $^{1}$ (Curve parameter c) } \\
\hline Age & $-4.8 \times 10^{-6}$ & 0.774 & $-7.2 \times 10^{-6}$ & -0.061 & $-0.00004-0.00002$ & 0.643 \\
\hline Sex & $-7.3 \times 10^{-5}$ & 0.746 & $-2.5 \times 10^{-5}$ & -0.016 & $-0.0004-0.0004$ & 0.901 \\
\hline Height & 0.001 & 0.586 & & & & \\
\hline$C_{\text {baseline }}$ & -0.406 & 0.033 & -0.345 & -0.254 & $-0.695-0.006$ & 0.054 \\
\hline$\Delta$ weight & $7.5 \times 10^{-6}$ & 0.762 & B & & & \\
\hline$\Delta \mathrm{FEV}_{1}$ & 0.001 & 0.001 & 0.001 & 0.372 & $0.0002-0.002$ & 0.013 \\
\hline$\Delta \mathrm{FVC}$ & 0.001 & $<0.001$ & & & & \\
\hline$\Delta \mathrm{C}_{\text {rest }}(\mathrm{L})$ & 0.0005 & 0.025 & 0.0004 & 0.268 & $-0.00002-0.001$ & 0.192 \\
\hline$\Delta \mathrm{I} \mathrm{C}_{\text {dynamic }}(\mathrm{L})$ & 0.0001 & 0.651 & -0.001 & -0.249 & $-0.001-0.0002$ & 0.179 \\
\hline \multirow[t]{2}{*}{$\Delta \mathrm{IRV}$} & -0.0003 & 0.280 & & & & \\
\hline & & & & & & $R^{2}=0.315$ \\
\hline
\end{tabular}

$95 \%$ confidence interval $(\mathrm{Cl})$ examined by linear regression in bivariate and multivariate analyses

CPET: cardio pulmonary exercise test; $\triangle$ weight: weight at CPET2 minus weight at $\mathrm{CPET}_{1} ; \mathrm{FEV}_{1}$ : forced expired volume in one second, $\triangle \mathrm{FEV} \mathrm{V}_{1}$ : FEV ${ }_{1}$ at $\mathrm{CPET}_{2}$ minus FEV 1 at CPET1; FVC: forced vital capacity; $\triangle$ FVC: FVC at CPET2 minus FVC at CPET1; IC: inspiratory capacity; $\triangle I C_{\text {rest }}$ was calculated as IC at rest at CPET2 minus IC at rest at CPET 1; $\triangle \mathrm{IC}$ was calculated as IC at start of the test minus IC at the end of the test; $\triangle \mathrm{I} \mathrm{C}_{\text {dynamic }}$ was calculated as $\triangle \mathrm{IC}$ at CPET2 minus $\triangle \mathrm{IC}$ at CPET1; IRV: inspiratory reserve volume; $\triangle \mathrm{IRV}$ was calculated as IRV at CPET2 minus IRV at CPET1; $a_{\text {baseline: }}$ curve parameter a at baseline; $b_{\text {baseline: }}$ curve parameter $b$ at baseline; $c_{\text {baseline: }}$ curve parameter $c$ at baseline; $R^{2}$ : The coefficient of determination

${ }^{1}$ The relationship between ventilation $\left(\dot{V}_{E}\right)$ and tidal volume $\left(V_{T}\right)$ was described by a quadratic model $\left(V_{T}=a+b \cdot \dot{V}_{E}+c \cdot \dot{V}_{E}^{2}\right)$, and the a, b, and $c$ were calculated as the difference between CPET2 minus CPET1

*St.B: Standardised beta 
ECLIPSE study [10]. Without participation in pulmonary rehabilitation, the decline in $\dot{\mathrm{V}}_{2 \text { peak }}$ and $\dot{\mathrm{V}}_{\text {Epeak }}$ could have been larger, resulting in an even stronger association with the predictors.

Self-reported physical activity was not measured synchronized with the second CPET, but was part of the data collection at baseline, and at one and three year follow-up in BCCS. We have previously shown that patients who participated in pulmonary rehabilitation were more physically active than those who had not [27]. We assume that the physical activity level would not be substantially different from this recording.

The dropout rate from baseline to follow-up after a mean time of 4.5 years was $29 \%$. The patients were lost to follow-up mainly because of death or disease severity. In the study of Oga et al. [12] the dropout rate was $51 \%$. In longitudinal observational studies with the 6 min walking distance as the main outcome and a follow-up period of 3-5 years, the dropout rate varied between 31-34 \% [35-37]. With a progressive disease, an increasing dropout rate over time is unavoidable and as compared with previous studies our dropout rate is not considered high.

\section{Conclusions}

There was a significant reduction in $\dot{\mathrm{V}}_{2 \text { peak }}$ and $\dot{\mathrm{V}}_{\text {Epeak }}$ over 4.5 years in this group of COPD patients. The changes were related to an increase in lung hyperinflation and a reduction in $\mathrm{FEV}_{1}$ along with persistent smoking during the study period. The breathing pattern changed towards a lower $\mathrm{V}_{\mathrm{Tmax}}$ and a lower $\mathrm{V}_{\mathrm{T}}$ at a given $\dot{\mathrm{V}}_{\mathrm{E}}$ and the reduction in $\mathrm{FEV}_{1}$ predicted these changes. The findings indicate that optimal treatment of airway obstruction and lung hyperinflation, and smoking cessation are all important in optimizing functional capacity in COPD along with physical training programs.

\section{Competing interests}

The authors declare that they have no competing interests.

\section{Authors' contributions}

Concept and design (BF, ET, JAH, TMLE, PSB). Data collection (BF, JAH, TMLE, PSB, ET). Data analyses and interpretation (BF, BE, RMN, JAH, LIS, ET). Drafting the manuscript (BF, ET, BS, LIS, JAH, RMN). All the authors have revised and approved the final manuscript.

\section{Acknowledgements}

The authors thank Eli Nordeide, Lene Svendsen and Michael Storebø for participation in data collection and for help in organizing the study. We also wish to acknowledge the patients who participated in the study.

\section{Author details}

${ }^{1}$ Centre for Evidence-Based Practice, Bergen University College, Bergen, Norway. ${ }^{2}$ Department of Clinical Science, University of Bergen, Bergen, Norway. ${ }^{3}$ Department of Global Public Health and Primary Care, University of Bergen, Bergen, Norway. ${ }^{4}$ Department of Physiotherapy, Haukeland University Hospital, Bergen, Norway. ${ }^{5}$ Department of Thoracic Medicine, Haukeland University Hospital, Bergen, Norway. ${ }^{6}$ Department of Occupational Medicine, Haukeland University Hospital, Bergen, Norway.
Received: 27 February 2015 Accepted: 6 August 2015

Published online: 19 August 2015

\section{References}

1. Parshall MB, Schwartzstein RM, Adams L, Banzett RB, Manning HL, Bourbeau J, et al. An official American Thoracic Society statement: update on the mechanisms, assessment, and management of dyspnea. Am J Respir Crit Care Med. 2012;185:435-52.

2. Spruit MA, Singh SJ, Garvey C, ZuWallack R, Nici L, Rochester C, et al. An official American Thoracic Society/European Respiratory Society statement: key concepts and advances in pulmonary rehabilitation. Am J Respir Crit Care Med. 2013;188:e13-64.

3. Guenette JA, Chin RC, Cheng S, Dominelli PB, Raghavan N, Webb KA, et al. Mechanisms of exercise intolerance in global initiative for chronic obstructive lung disease grade 1 COPD. Eur Respir J. 2014;44:1177-87.

4. Hyatt RE. Expiratory flow limitation. J Appl Physiol. 1983;55:1-7.

5. O'Donnell DE, Webb KA. Exertional breathlessness in patients with chronic airflow limitation. The role of lung hyperinflation. Am Rev Respir Dis. 1993;148:1351-7

6. Somfay A, Porszasz J, Lee SM, Casaburi R. Effect of hyperoxia on gas exchange and lactate kinetics following exercise onset in nonhypoxemic COPD patients. Chest. 2002;121:393-400.

7. Gosselink R, Troosters T, Decramer M. Peripheral muscle weakness contributes to exercise limitation in COPD. Am J Respir Crit Care Med. 1996;153:976-80.

8. Seymour JM, Spruit MA, Hopkinson NS, Natanek SA, Man WD, Jackson A, et al. The prevalence of quadriceps weakness in COPD and the relationship with disease severity. Eur Respir J. 2010;36:81-8.

9. Tashkin DP, Celli B, Senn S, Burkhart D, Kesten S, Menjoge S, et al. A 4-year trial of tiotropium in chronic obstructive pulmonary disease. N Engl J Med. 2008;359:1543-54.

10. Vestbo J, Edwards LD, Scanlon PD, Yates JC, Agusti A, Bakke P, et al. Changes in forced expiratory volume in 1 second over time in COPD. $\mathrm{N}$ Engl J Med. 2011;365:1184-92.

11. Palange P, Ward SA, Carlsen KH, Casaburi R, Gallagher CG, Gosselink R, et al. Recommendations on the use of exercise testing in clinical practice. Eur Respir J. 2007:29:185-209. Epub 2007/01/02.

12. Oga T, Nishimura K, Tsukino M, Sato S, Hajiro T, Mishima M. Exercise capacity deterioration in patients with COPD: longitudinal evaluation over 5 years. Chest. 2005;128:62-9. Epub 2005/07/09.

13. Gallagher CG, Brown E, Younes M. Breathing pattern during maximal exercise and during submaximal exercise with hypercapnia. J Appl Physiol. 1987:63:238-44.

14. O'Donnell DE, Hamilton AL, Webb KA. Sensory-mechanical relationships during high-intensity, constant-work-rate exercise in COPD. J Appl Physiol. 2006;101:1025-35.

15. Cotes JE. Response to progressive exercise: a three-index test. $\mathrm{Br} J$ Dis Chest. 1972;66:169-84

16. Neder JA, Dal Corso S, Malaguti C, Reis S, De Fuccio MB, Schmidt H, et al. The pattern and timing of breathing during incremental exercise: $a$ normative study. Eur Respir J. 2003;21:530-8.

17. Hey EN, Lloyd BB, Cunningham DJ, Jukes MG, Bolton DP. Effects of various respiratory stimuli on the depth and frequency of breathing in man. Respir Physiol. 1966;1:193-205.

18. Frisk B, Espehaug B, Hardie JA, Strand LI, Moe-Nilssen R, Eagan TM, et al. Airway obstruction, dynamic hyperinflation, and breathing pattern during incremental exercise in COPD patients. Physiol Rep. 2014;2:e00222.

19. Eagan TM, Ueland T, Wagner PD, Hardie JA, Mollnes TE, Damas JK, et al. Systemic inflammatory markers in COPD: results from the Bergen COPD Cohort Study. Eur Respir J. 2010;35:540-8. Epub 2009/08/01.

20. Johannessen A, Lehmann S, Omenaas ER, Eide GE, Bakke PS, Gulsvik A. Post-bronchodilator spirometry reference values in adults and implications for disease management. Am J Respir Crit Care Med. 2006;173:1316-25. Epub 2006/03/25.

21. Rabe KF, Hurd S, Anzueto A, Barnes PJ, Buist SA, Calverley P, et al. Global strategy for the diagnosis, management, and prevention of chronic obstructive pulmonary disease: GOLD executive summary. Am J Respir Crit Care Med. 2007;176:532-55.

22. Miller MR, Hankinson J, Brusasco V, Burgos F, Casaburi R, Coates A, et al. Standardisation of spirometry. Eur Respir J. 2005;26:319-38. 
23. Bruce RA. Exercise testing of patients with coronary heart disease. Principles and normal standards for evaluation. Ann Clin Res. 1971;3:323-32.

24. Bruce RA, Kusumi F, Hosmer D. Maximal oxygen intake and nomographic assessment of functional aerobic impairment in cardiovascular disease. Am Heart J. 1973;85:546-62.

25. Borg G. Borg's Perceived exertion and pain scales, vol. viii. Champaign, IL: Human Kinetics; 1998. p. 104.

26. Gandevia B, Hugh-Jones P. Terminology for measurements of ventilatory capacity; a report to the thoracic society. Thorax. 1957;12:290-3.

27. Frisk B, Espehaug B, Hardie JA, Strand LI, Moe-Nilssen R, Eagan TM, et al. Physical activity and longitudinal change in 6-min walk distance in COPD patients. Respir Med. 2014;108:86-94.

28. Kurtze N, Rangul V, Hustvedt BE, Flanders WD. Reliability and validity of self-reported physical activity in the Nord-Trondelag Health Study (HUNT 2). Eur J Epidemiol. 2007:22:379-87.

29. Kurtze N, Rangul V, Hustvedt BE, Flanders WD. Reliability and validity of self-reported physical activity in the Nord-Trondelag Health Study: HUNT 1. Scand J Public Health. 2008;36:52-61.

30. Stubbing DG, Pengelly LD, Morse JL, Jones NL. Pulmonary mechanics during exercise in subjects with chronic airflow obstruction. J Appl Physiol. 1980;49:511-5

31. Yan S, Kaminski D, Sliwinski P. Reliability of inspiratory capacity for estimating end-expiratory lung volume changes during exercise in patients with chronic obstructive pulmonary disease. Am J Respir Crit Care Med. 1997;156:55-9

32. Vogiatzis I, Georgiadou O, Golemati S, Aliverti A, Kosmas E, Kastanakis E, et al. Patterns of dynamic hyperinflation during exercise and recovery in patients with severe chronic obstructive pulmonary disease. Thorax. 2005;60:723-9

33. Laveneziana P, Guenette JA, Webb KA, O'Donnell DE. New physiological insights into dyspnea and exercise intolerance in chronic obstructive pulmonary disease patients. Expert Rev Respir Med. 2012;6:651-62.

34. Casaburi R. Factors determining constant work rate exercise tolerance in COPD and their role in dictating the minimal clinically important difference in response to interventions. COPD. 2005:2:131-6.

35. Casanova C, Cote CG, Marin JM, de Torres JP, Aguirre-Jaime A, Mendez R et al. The 6-min walking distance: long-term follow up in patients with COPD. Eur Respir J. 2007;29:535-40. Epub 2006/11/17.

36. Kapella MC, Larson JL, Covey MK, Alex CG. Functional performance in chronic obstructive pulmonary disease declines with time. Med Sci Sports Exerc. 2011;43:218-24. Epub 2010/06/15

37. Spruit MA, Polkey MI, Celli B, Edwards LD, Watkins ML, Pinto-Plata V, et al. Predicting outcomes from 6-minute walk distance in chronic obstructive pulmonary disease. J Am Med Dir Assoc. 2012;13:291-7. Epub 2011/07/23.

\section{Submit your next manuscript to BioMed Central and take full advantage of:}

- Convenient online submission

- Thorough peer review

- No space constraints or color figure charges

- Immediate publication on acceptance

- Inclusion in PubMed, CAS, Scopus and Google Scholar

- Research which is freely available for redistribution 